\title{
ASPECTOS IMPULSIONADORES DO POTENCIAL INOVADOR DA INDÚSTRIA TÊXTIL E DE CONFECÇÃO NO DISTRITO CRIATIVO DE FLANDRES: INSPIRAÇÕES PARA A FORMULAÇÃO DE POLÍTICAS NO BRASIL
}

\section{ASPECTS THAT BOOST INNOVATIVE POTENTIAL OF TEXTILE AND APPAREL INDUSTRY IN FLANDERS DISTRICT OF CREATIVITY: INSPIRATIONS FOR THE DESIGN OF POLICIES IN BRAZIL}

\author{
Flavio da Silveira Bruno*E-mail: fbruno@cetiqt.senai.br \\ Henrique Fonseca Netto** E-mail: fonseca@pep.ufri.br \\ Ana Cristina Martins Bruno* E-mail: anabruno@cetiqt.senai.br \\ *SENAI/CETIQT, Rio de Janeiro, RJ \\ ${ }^{* *}$ COPPE/UFRJ, Rio de Janeiro, RJ
}

Resumo: Este trabalho tem como objetivo identificar aspectos da economia criativa da região de Flandres que influem no desempenho da cadeia de valor têxtil e de confecção local, a fim de contribuir para a formulação de políticas de apoio à criatividade empresarial do setor no Brasil. Entrevistas e observações em instituições selecionadas foram realizadas durante missão prospectiva à região de Flandres. As informações coletadas foram então confrontadas com a literatura teórica e técnica selecionada que analisa as economias regionais baseadas em indústrias criativas. Embora os resultados não revelem evidências de uma coordenação explícita da rede de valor decorrente de políticas específicas destinadas a agregar valor aos produtos têxteis e de vestuário belga, eles sugerem que o desempenho das principais instituições públicas e privadas associado a iniciativas mais amplas de estímulo a Pesquisa e Desenvolvimento do setor na Europa, promovidas pela EURATEX, apoiam a criatividade para a inovação e são bases essenciais para o desenvolvimento de empreendedores criativos.

Palavras-chave: Distritos de Criatividade. Economia criativa. Têxtil e confecção. Empreendedorismo. Inovação.

Abstract: This work aims to identify aspects of the creative economy in the region of Flanders that influence the performance of the textile and apparel value chain in order to contribute to the design of policies that can enhance the entrepreneurial creativity of this sector in Brazil. Interviews and observations were conducted during a prospective mission to the region of Flanders. Information collected was then confronted with selected theoretical and technical literature that analyze regional economies based on creative industries. Although the results reveal no evidence of an explicit coordination of the value network resulting from specific policies designed to add value to Belgian textile and apparel products, they suggest that the performance of key public and private institutions associated with broader initiatives to stimulate Research and Development in the sector in Europe, promoted by EURATEX, supports creativity for innovation and are essential foundations for the development of creative entrepreneurs.

Key-words: Districts of Creativity. Creative economy. Textile and apparel. Entrepreneurship. Innovation. 


\section{INTRODUÇÃO}

Iniciativas para impulsionar a capacidade competitiva da indústria têxtil e de confecção brasileira parecem apontar para duas necessidades prementes: aumentar a capacidade de produzir inovações e intensificar a internacionalização das empresas do setor (LUPATINI, 2004; GARCIA et alii, 2005; ABDI, 2009a; 2009b; 2009c; BRUNO; BRUNO, 2009; BRUNO, 2007; BRUNO et alii, 2007). Nas grandes indústrias têxteis consolidadas por processos de características globais, a internacionalização tem ocorrido como resultado natural do processo de incorporação de empresas de atuação restrita por megacorporações transnacionais. O equacionamento do futuro do setor como um todo, entretanto, parece depender da reformulação estrutural e conceitual dos elos finais da cadeia, onde o segmento de confecção, em que prevalecem pequenas e médias empresas (PME) intensivas no uso de mão-de-obra pouco qualificada e historicamente caracterizadas como sendo de baixa intensidade tecnológica (OECD, 2005; IBGE, 2005), apresenta-se como o principal gargalo à modernização.

Alvo de políticas desenvolvimentistas de curto prazo - preocupadas com a geração de emprego e renda nas classes mais pobres - que investem na estruturação e coordenação de agrupamentos de empresas em Arranjos Produtivos Locais como motor de crescimento regional, o segmento de PME de confecção tem sido analisado pela academia e pelo governo brasileiro ao longo dos últimos anos, em busca da identificação de padrões para a formulação de políticas (TENDLER, 2002; BNDES, 2004a; 2004b; SEBRAE, 2004; SUZIGAN et alii, 2003; 2007). Ações de fomento à cultura empreendedora fundamentadas na abertura de negócios têm resultado na especialização de regiões brasileiras em segmentos de produtos, adotando muitas vezes modelos excessivamente pragmáticos que ignoram a necessidade da abordagem multicritério que considere a sustentabilidade de longo prazo do crescimento econômico (SUZIGAN 2007). Em algumas dessas regiões, multiplicam-se empresas em concorrência direta que têm no baixo preço o principal fator de competitividade.

Alinhado com os resultados do Estudo Prospectivo Setorial Têxtil e de Confecção (ABDI, 2009a) este trabalho assume que, para aumentar a capacidade de inovação e de internacionalização das PME brasileiras de confecção, outros modelos de desenvolvimento regional precisam ser adotados, modelos que Revista Produção Online. Florianópolis, SC, v.11, n. 4, p. 1028-1058, out./dez. 2011. 
ultrapassem a mera coordenação racional e teleológica de atividades produtivas isoladas.

Distrito de Criatividade é uma denominação adotada pelo Flanders DC, instituição governamental belga que atua para o fortalecimento da criatividade empreendedora na região de Flandres. Os DCs, como são chamados os Distritos de Criatividade, estendem-se por quase todos os continentes, formando uma rede composta por 13 regiões. Essas regiões têm em comum a adoção de políticas de apoio à criatividade empreendedora, fomentando economias baseadas em inovação e internacionalização. A rede de DCs estimula a troca de experiências entre si, gerando a aprendizagem mútua das melhores práticas individuais (FLANDERS DC, 2009).

Tais economias que têm no empreendedorismo, na inovação e na criatividade seus motores, são chamadas de Economias Criativas (ARTHUR D. LITTLE, 2006; BRAUN; LAVANGA, 2007; EUROPEAN..., 2006; MINISTERIAL..., 2001; UNCTAD, 2010). Nessa abordagem, a inovação está associada às interações constantes e intensas entre atores produtivos, comerciais e consumidores. Trata-se, pois, de um processo de aprendizagem em que o ambiente social desempenha papel essencial (LUNDVALL, 1992; 2005; FLORIDA, 1995). O caráter territorial e suas relações com a cultura nele estabelecida são pontos centrais nessa abordagem econômica que procura fomentar políticas de apoio ao empreendedor inovador que não se restrinjam aos aspectos meramente tecnológicos. As características culturais e artísticas dessas regiões atraem talentos potencializados por políticas públicas de estímulo à inovação, promoção do empreendedorismo, suporte para acesso ao capital de risco, desenvolvimento do mercado, desenvolvimento de clusters e salvaguardas para a propriedade industrial. Tais políticas facilitam os empreendedores criativos a desenvolver seus mercados domésticos, e, principalmente, seus mercados no exterior. Regiões que aprendem podem evoluir até se tornar centros de captação e de geração de conhecimento e de idéias porque promovem o ambiente e a infraestrutura que facilitam o fluxo de conhecimento, idéias e aprendizagem.

Uma região que exerce influência no capital humano disponível cria um ambiente mais favorável à criatividade, propiciando a efetivação de negócios com foco nos fatores regionais (ARTHUR D. LITLLE, 2006; DE VOLDERE et alii, 2006).

Revista Produção Online. Florianópolis, SC, v.11, n. 4, p. 1028-1058, out./dez. 2011. 
No Brasil, florescem iniciativas nos âmbitos federal, estadual e municipal que enfatizam a criatividade como valor intangível capaz de promover desenvolvimento socioeconômico. A nova Secretaria de Economia Criativa do Ministério da Cultura reforça a intenção de canalizar para o desenvolvimento socioeconômico local e regional os valores e patrimônios artísticos e culturais dissipados e erodidos pela adoção sistemática de modelos de desenvolvimento excessivamente industrialistas.

Em novembro de 2010, foi acatada pelo Comitê Político da Rede Mundial de Distritos de Criatividade a candidatura da cidade do Rio de Janeiro como novo membro, juntamente com a cidade de Copenhagen. A cidade do Rio de Janeiro também foi escolhida como a sede do Fórum Mundial de DC, vencendo sua concorrente finlandesa Tampere, uma das primeiras integrantes da rede. A iniciativa da prefeitura foi deflagrada a partir dos estudos do Instituto de Prospecção Tecnológica e Mercadológica (IPTM) do SENAI/CETIQT. O IPTM vem trabalhando em parceria com a Subsecretaria de Patrimônio Cultural, Arquitetura, Urbanismo e Design e com o Instituto Pereira Passos, para a consolidação da identidade do RioDC (BRUNO et alii, 2011).

Este trabalho tem como objetivo identificar aspectos da economia criativa da região de Flandres que influem no desempenho da cadeia de valor têxtil e de confecção local, a fim de contribuir para a formulação de políticas de apoio à criatividade empresarial do setor no Brasil. Pretende-se orientar a identificação dos principais aspectos que devam ser priorizados por políticas setoriais que adotem a indústria criativa da moda como motor de desenvolvimento. A partir de referencial teórico fundamentado na ciência regional com enfoque em economias criativas, são analisadas informações levantadas em missão técnica a instituições selecionadas da região de Flandres, realizada em dezembro de 2008.

O trabalho está organizado da seguinte forma: a seção dois apresenta a evolução do conceito de economia criativa a partir da revisão da literatura, complementando a abordagem com teorias que compõem a ciência regional. $\mathrm{Na}$ seção três, são sintetizadas as informações recolhidas na missão a Flandres, descrevendo características das instituições visitadas e analisando seu papel na rede de valor T\&C local. A seção quatro sintetiza as características principais da economia criativa local, com base nas análises das instituições visitadas, que poderão servir de inspiração para a formulação, no Brasil, de políticas que 
amplifiquem capacidades regionais do setor no mercado global A seção cinco apresenta as considerações finais e recomendações para trabalhos futuros.

\section{A ECONOMIA CRIATIVA E OS DISTRITOS DE CRIATIVIDADE}

Países e regiões procuram avidamente por novas formas de impulsionar e manter seu crescimento econômico e social em um mundo em que a competição global é marcada por preços cada vez mais baixos e condições de trabalho muitas vezes inaceitáveis. No novo ambiente criado pela globalização, onde os continentes separados pelas forças da natureza foram reintegrados pelas forças sociais, tecnológicas e econômicas, prevalecem espécies empresariais mais agressivas, mais habituadas a competir por fatores e recursos escassos. Neste processo de darwinismo empresarial, criatividade e inovação voltam à cena como os motores que impulsionarão novos empreendedores a distanciarem-se de seus competidores para satisfazer necessidades sempre mais exigentes dos mercados mais ricos. Em um mundo em que sobrevive o mais adaptado, essas duas dimensões emergem justamente porque induzem os atores empresariais à adaptação ao novo, ao mesmo tempo em que fortalecem sua capacidade de introduzir novos e desconhecidos padrões, rompendo com a ordem estabelecida (ARTHUR D. LITTLE, 2006; KAPLINSKY, 2004; SCHUMPETER, 2004; 2011).

O problema da localização das atividades produtivas é compendiado por Benko (1998), sintetizando, cronologicamente, as principais escolas da ciência regional e seus principais autores. Benko (op. cit. p.57) considera que a maioria dos estudos tem objetivos meramente descritivos quando a principal finalidade da teoria da localização espacial de empreendimentos industriais seria de fornecer uma explicação para a organização espacial das firmas, identificando as variáveis que determinam a localização e oferecendo soluções analíticas. A formulação de políticas depende dessa capacidade da pesquisa. Suzigan et alii (2007) constatam haver ampla literatura enfatizando teorias explicativas para a existência de clusters mas, em contrapartida, afirmam haver poucos trabalhos que abordem a formulação de políticas, especialmente para países em desenvolvimento. No contexto urbano, as análises são voltadas para as cidades criativas. Florida (2002) é o autor seminal cuja principal contribuição talvez tenha sido a de quebrar as noções convencionais 
que associam a cultura a comportamentos frívolos ou derivativos (LESLIE, 2005). Alguns autores, entretanto, mostram que a libertação da cultura fordista não é tão fácil (VANOLO, 2008). Há ainda aqueles que consideram que a adoção dos princípios de Florida pode acarretar retrocessos na cultura criativa de uma cidade, como seria o caso em Austin, cidade criativa modelo para Florida e seguidores (LONG, 2009).

Desde a década de 1990, crescem em importância nos EUA e na Europa os estudos sobre a geografia econômica das indústrias criativas (IC), discutindo-se a interdependência entre a produção de bens e serviços dessas indústrias e o espaço. O peso crescente dessas atividades no conjunto da economia mundial é reforçado pelo caráter de responsabilidade socioambiental que indústrias como a de moda vêm assumindo para si (SILVA, 2008; ABDI, 2009a).

Conhecimento e aprendizagem são ativos fundamentais nas economias modernas. Sendo o processo de aprendizagem essencialmente interativo, deve ser entendido em seu contexto institucional e cultural. Por outro lado, pesquisas empíricas sobre a geografia econômica mostram que o processo inovativo é de natureza localizada e socialmente enraizado, sendo difícil de ser movido de um lugar para outro. Sob esses aspectos, as regiões são elementos-chave na era do capitalismo global baseado em conhecimento, tornando-se pontos focais para a criação de conhecimento e aprendizagem desde que assumam as características de regiões que aprendem. Existem diferentes concepções de sistemas nacionais de inovação. Em nosso caso, assumimos sua definição mais ampla, que não se restringe apenas às interações entre empresas e instituições científicas. Nessa abordagem, proposta por Lundvall (2005), a inovação está associada às interações constantes e intensas entre atores produtivos, comerciais e consumidores. Trata-se, pois, de um processo de aprendizagem em que o ambiente social desempenha papel essencial (LUNDVALL, 1992; 2005; FLORIDA, 1995).

Estratégias de negócio orientadas pelo design e que repousam em contextos socioculturais são também objeto da abordagem Product-Service System, que repensa as relações entre consumo e condições de vida e reforça a importância dos serviços, da cultura e das tradições de um local na formulação de políticas socioeconômicas em países em desenvolvimento (MANZINI; VEZZOLI, 2002a). Para alguns autores (cf. MANZINI; VEZZOLI, 2002b; 2008; JONES; STANTON; Revista Produção Online. Florianópolis, SC, v.11, n. 4, p. 1028-1058, out./dez. 2011. 
HARRISON, 2001), a abordagem sustentável é entendida como impulsionadora da criatividade.

Em 1998, foi publicado pelo Departamento de Cultura, Mídia e Esporte do Reino Unido o primeiro mapeamento de IC. Trata-se de tentativa pioneira de medir a contribuição econômica dessas indústrias no Reino Unido, identificando ainda as oportunidades e ameaças que enfrentavam. O mapeamento também serviu para esboçar um conjunto de ações a serem seguidas por governo e iniciativa privada. No documento, a definição de IC é dessa forma estabelecida:

Those industries which have their origin in individual creativity, skill and talent and which have a potential for wealth and job creation through the generation and exploitation of intellectual property (MINISTERIAL..., 2001, p.5).

Braun e Lavanga (2007) produziram um levantamento financiado pelo governo holandês sobre políticas explícitas de diferentes nações para as IC. O estudo internacional teve cunho exploratório e comparativo concentrando-se em políticas que tivessem como objetivo estimular o desenvolvimento econômico dessas indústrias. O levantamento considerou, entre outras, as seguintes políticas econômicas para as IC: estímulo à inovação; promoção do empreendedorismo; suporte para acesso ao capital de risco; desenvolvimento do mercado, facilitando empreendedores criativos a desenvolver seus mercados domésticos, e, principalmente, seus mercados no exterior; impulso ao desenvolvimento de clusters; e salvaguardas para a propriedade intelectual (BRAUN, LAVANGA, 2007, p. i).

Braun e Lavanga (op.cit.) identificaram ainda outros mapeamentos, similares ao estudo pioneiro realizado no Reino Unido, elaborados, entre 2000 e 2006, na Dinamarca, Alemanha, Austrália, Nova Zelândia, Espanha, Áustria, Singapura, Holanda e Bélgica. O conceito estende-se na noção de Distritos de Criatividade (DC) e diversas dimensões compõem o desenvolvimento criativo e inovador no âmbito das economias regionais. Nesse contexto, dimensões como empreendedorismo, cooperação, internacionalização, transferência de conhecimento e de tecnologia, financiamentos disponíveis, marketing regional, propriedade intelectual e ecossistema industrial, relacionam-se com ecossistema científico, desenvolvimento de clusters, autoridades públicas responsivas e inovadoras, inovação social, suporte às MPME, educação e competências, cultura, e infraestrutura física (ARTHUR D. LITTLE, 2006). 
Em 2004, o Flanders District of Creativity implementou uma rede mundial de regiões criativas, com o objetivo de trocar experiências e aprendizado sobre suas políticas econômicas. Membros dessa rede têm competências regionais suficientes para desenvolver estratégia econômica própria e para agir de acordo com ela, no que se refere ao mercado de trabalho, à economia e, também, em áreas como educação, ciência e inovação. Nessas regiões, prevalecem as abordagens abertas e criativas, vitais para o aproveitamento dos benefícios da diversidade cultural, econômica e geográfica, característica da rede de DC. O que as une é o estímulo à elaboração de políticas e o reconhecimento de que a criatividade, a inovação e a visão empreendedora são fatores decisivos para o aumento da competitividade regional, para o crescimento econômico e, principalmente, para a proteção e a melhoria do bem estar de seus cidadãos. O posicionamento de cada um desses distritos na economia criativa baseada em conhecimento foi investigado por De Voldere et alii (2006). Os autores (op. cit, p.11) definem a criatividade como a capacidade de encontrar soluções inovadoras para os problemas, de criar novos produtos ou processos e, desta forma, de contribuir para a criação de valor econômico. A criatividade está claramente relacionada à inovação e ao empreendedorismo, para garantir sua transformação em oportunidades de mercado.

No modelo econômico dessas regiões, a economia é dirigida pela criatividade, traduzida em inovação, visão empreendedora e internacionalização. Esses são os três pilares da economia criativa. A inovação é o processo de transformar novas idéias em novos produtos ou novos procedimentos que levem a ganhos de produtividade. O empreendedorismo transforma esses esforços de inovação em oportunidades de mercado. E, finalmente, a internacionalização das atividades é o terceiro crucial processo na economia criativa, visto que os mercados regionais são pequenos para a atuação das empresas em grande escala. Para gerar crescimento econômico, os três processos de criatividade precisam estar em constante interação.

A inovação sem as necessárias relações com empreendedorismo e internacionalização, provavelmente, não leva ao crescimento econômico, uma vez que as idéias não são traduzidas ao mercado. A combinação de inovação, empreendedorismo e internacionalização é o que se denomina criatividade empreendedora, maior fonte de crescimento econômico na economia criativa. Os 
autores acreditam que regiões que aplicam com habilidade esses fatores têm grande probabilidade de alcançar desempenho econômico superior.

Florida (1995, p.534) sugere que determinadas regiões que aprendem, evoluem até se tornarem centros de captação e de geração de conhecimento e de idéias porque promovem o ambiente e a infraestrutura que facilitam o fluxo de conhecimento, idéias e aprendizagem. Uma região que exerce influência no capital humano disponível cria um ambiente mais favorável à criatividade, propiciando a efetivação de negócios com foco nos fatores regionais. Com ações de cunho inovador e visão empreendedora, o olhar é estendido para além das fronteiras geográficas, captando oportunidades do mercado exterior e fortalecendo a competitividade local, o que contribui para o bem estar de seus residentes. A prosperidade, por sua vez, influi na melhoria da qualidade de vida, o que termina por atrair mais pessoas criativas para a região, impulsionando ainda mais sua atividade econômica. Todos esses fatores são, assim, insumos que se transformam em crescimento econômico, bem estar e qualidade de vida, resultados da economia criativa, obtidos por meio da criatividade empreendedora, ou seja, por intermédio da combinação dos processos de inovação, visão empreendedora e internacionalização. Regiões e cidades no mundo têm reforçado seu papel como Distritos de Criatividade. Flandres é uma delas. Uma região que exerça influência no capital humano disponível e estabeleça o ambiente favorável à criatividade, gerando negócios com foco simultâneo em fatores tangíveis e intangíveis impulsionará a inovação e o empreendedorismo. Olhando além de suas fronteiras para aproveitar ao máximo as oportunidades de exportação, reforçará sua competitividade e criará riqueza para seus residentes. Em troca, melhor qualidade de vida e bem estar. Uma região que possa garantir um bom padrão de vida para seus residentes atrairá mais pessoas para o que Richard Florida chamou de Classe Criativa, produzindo mais atividades econômicas. Este círculo coeso de elementos que interagem mutuamente é o modelo de DC na Economia Criativa (DE VOLDERE, 2006).

Os inputs de um DC incluem o estímulo à educação - para criação de um ambiente humano que anseie aprender e adaptar-se a novos mercados em desenvolvimento - e às instituições que impulsionem a criatividade tão longe quanto possível. Seu crescimento econômico é resultado de seu desenvolvimento. Uma região que não deseje mais competir com base apenas em eficiência e preços Revista Produção Online. Florianópolis, SC, v.11, n. 4, p. 1028-1058, out./dez. 2011. 
baixos, deve voltar-se para atividades mais intensivas em conhecimento, tornandose uma economia em que a criatividade é traduzida em inovação, internacionalização e empreendedorismo sustentável.

Pesquisas empíricas revelaram as condições para o desenvolvimento de uma economia criativa: cooperação; liderança e gestão; flexibilidade e proatividade; metatecnologia; inovação sem imitação. Dezesseis dimensões foram sintetizadas a partir da análise de casos e da literatura pela Arthur D. Little (op. cit.):

i. Empreendedorismo: ocorrência e estímulo à criatividade e ao comportamento empreendedor.

ii. Cooperação: ocorrência e estímulo para intensa colaboração e atuação em rede entre vários stakeholders (públicos e privados).

iii. Internacionalização: ocorrência e estímulo para internacionalização de negócios.

iv. Conhecimento e transferência tecnológica: ocorrência e estímulo para transferência de conhecimento e de tecnologia entre parceiros.

v. Financiamento: ocorrência e provisão de fundos privados e públicos que cubram as diversas fases do desenvolvimento de negócios e dos tipos de inovação e de atividades criativas.

vi. Marketing regional: criação de marcas e promoção da identidade regional no exterior com ênfase em suas propriedades únicas.

vii. Propriedade intelectual $(\mathrm{PI})$ : existência de estratégias claras de proteção à $\mathrm{PI} e$ presença de organizações que orientem empreendedores e negócios em questões de PI.

viii. Ecossistema industrial: ocorrência e estímulo para uma densa e diversa rede industrial com empresas iniciantes, gazelles (crescem $+20 \% / a n o$ ), e negócios maduros.

ix. Ecossistema científico: ocorrência e estímulo para uma densa e diversa rede científica (compreendendo centros de pesquisa públicos e privados) na qual seja atribuído um prêmio a P\&D de vanguarda e a interdisciplinaridade.

x. Cluster: ocorrência e estímulo à formação de grupos geograficamente próximos e interconectados de empresas, indústrias e instituições associadas, em áreas específicas.

xi. Autoridades públicas inovadoras: presença de autoridades públicas participativas e de visão de futuro que sejam proativas às necessidades de 
conhecimento e de negócios, e que demonstrem ser inovadoras em formas de governança.

xii. Inovação no campo social: ocorrência e estímulo às inovações que sejam benéficas à sociedade como um todo e especialmente aos menos favorecidos.

xiii. Suporte às PME: existência de estratégias e de mecanismos de suporte especialmente desenhados para o desenvolvimento das PME.

xiv. Educação e competências: presença de investimentos específicos em educação e desenvolvimento de competências associados a iniciativas de desenvolvimento econômico.

xv. Cultura: emprego ambicioso e enfático da cultura, artes e criatividade como alavancas para a atração de talentos e para o desenvolvimento econômico.

xvi. Infraestrutura física: existência de estratégia específica e de investimento na infraestrutura que se apresente como instrumental para iniciativas de desenvolvimento econômico.

As interações sociais que ocorrem em um DC ultrapassam a mera relação entre fornecedores de uma cadeia produtiva. Uma região pode ser coordenada para gerar inovações que resultem do empreendedorismo criativo transferindo efetivamente conhecimentos, aprendizados e experiências aproveitando-se da proximidade entre os diversos atores. $\mathrm{O}$ ambiente criativo atrai talentos de diversas áreas, estabelecendo um processo de disseminação de uma cultura inovativa que transforma os padrões de desenvolvimento humano da região. A participação na rede de DC amplifica e diversifica as trocas de conhecimento e de experiências promovidas pela coordenação geral dos DCs. Um DC poderá promover um calendário de iniciativas e de ações, reunindo atividades artísticas, produtivas, comerciais, políticas e educacionais, amalgamadas em um processo cultural coordenado que transfira valor de uma atividade para outra. Uma atividade inspira outra, um talento atrai outro. Símbolos e valores são compartilhados em um processo sinérgico de desenvolvimento sustentável. A imagem do DC consolidada como uma região criativa é refletida para além de suas fronteiras administrativas. $A$ coordenação de políticas e de atividades reforça a eficiência e eficácia de ações institucionais, criando a infraestrutura necessária para os fluxos de conhecimento inovativo. 


\section{VISITAS E ENTREVISTAS EM INSTITUIÇÕES SELECIONADAS}

As instituições visitadas pela missão técnica na Bélgica foram selecionadas em função de sua representatividade na rede institucional belga de inovação têxtil. A representatividade foi estabelecida por estudo preliminar, realizado pelo Instituto de Prospecção Tecnológica e Mercadológica do SENAI/CETIQT (IPTM, 2008), em que foram identificadas instituições de pesquisa, ciência e inovação, e demais organizações que fazem parte da rede de apoio à inovação no setor têxtil e de confecção belga, tendo os seguintes atributos:

- Ações e iniciativas para contribuição à atividade empreendedora na cadeia de valor T\&C.

- Atividades relevantes de P\&D para o setor.

- Menção ou citação mútua em páginas da Internet e referências em relatórios técnicos e trabalhos científicos selecionados.

Além disso, a seleção teve por critério garantir a diversidade de papeis exercidos, com o intuito de permitir a identificação de pontos de vista e de racionalidades distintas em relação aos tópicos apresentados. Além das organizações sugeridas pelo estudo do IPTM, foi incluída no roteiro da missão a visita à empresa Picanol, um dos mais importantes fabricantes de teares do mundo $\mathrm{e}$ fornecedor tradicional de grandes empresas brasileiras de tecidos. As instituições visitadas representam de forma abrangente os ambientes político, científico, produtivo - de insumos e de bens de capital-, e institucionais de formação de designers e de apoio ao empreendedorismo. Todos os entrevistados pertenciam à alta administração das organizações visitadas:

European Apparel and Textiles Organisation (EURATEX): entrevista com Lutz Walter - Gerente Geral de P\&D

Belgian Textile Research Centre (CENTEXBEL): entrevista com Jan Laperre Diretor Geral e Bob Vander Beke - Diretor de Vendas e Mercado

Flanders District of Creativity (FLANDERS DC): entrevista com Pascal Cools Diretor Geral

Flanders Fashion Institute (FFI): entrevista com Edith Vervliet - Diretora Geral Comité Internationale de la Rayonne et des Fibres Synthétiques (CIRFS): entrevista com Colin M. Purvis - Diretor Geral 
Picanol: entrevista com Jan Maes - CRT Gerente Europa, África e América

\subsection{Visita à European Apparel and Textiles Organisation (EURATEX)}

Com sede na Rue Montoyer, em Bruxelas, EURATEX é uma organização sem fins lucrativos representativa da indústria T\&C europeia, e não especificamente da indústria belga. Seus membros são os 27 países da UE acrescidos da Turquia. Sua missão consiste em promover e defender os interesses de seus membros, respeitando a rede institucional europeia e suas obrigações internacionais (EURATEX, 2009).

O desempenho exportador da indústria T\&C belga pode ser, em parte, explicado pela capacidade de suas empresas de identificar oportunidades promissoras em novos nichos de mercado. Outro fator que deve ser considerado, segundo o entrevistado, é a infraestrutura institucional de suporte, como é o caso do instituto de pesquisa e de serviços técnicos CENTEXBEL e da Universidade de Gent, que realiza pesquisa fundamental em campos de interesse do setor. Note-se ainda, a existência de instituições de formação e de apoio à inovação de empresas, com estruturas-piloto que são oferecidas para que as empresas possam desenvolver produtos e processos. Esta rede ainda apresenta a vantagem de estar geograficamente concentrada. Em uma área restrita de Flandres localizam-se cerca de $80 \%$ das empresas. Além disso, há que se considerar a capacidade de operação no nível internacional de parte significativa da população belga devido ao domínio de quatro línguas: holandês, francês, inglês e alemão. As limitações de seu pequeno mercado nacional também impulsionam as empresas de Flandres para a internacionalização. De acordo com o entrevistado, existem poucas empresas que ainda confeccionam roupas na Bélgica, sendo grande parte da montagem feita em países do leste europeu, Tunísia, Turquia, e, evidentemente, na China.

Com relação às mudanças que deverão ser introduzidas pelos têxteis inteligentes na estrutura de governança e nas estratégias globais de produção, a introdução de insumos de alta intensidade tecnológica deverá implicar em alterações na lógica de competição por custos. A introdução de restrições técnicas e produtivas associadas à precisão e à qualidade necessárias para trabalhar com os novos 
materiais utilizados implica no controle de ativos escassos de conhecimento que distanciam os inovadores de seus concorrentes.

No que se refere às competências, o aumento da exigência técnica que garanta a funcionalidade, pode chegar ao ponto de exigir a eliminação do caráter de falibilidade do fator humano, eliminando sua atuação direta no sistema de produção. Outro problema gerado pelos novos têxteis é a necessidade de competências multidisciplinares, capazes de entender e de explorar conceitos característicos de cada sistema produtivo, têxtil e eletrônico, por exemplo. Por este motivo, é necessário desenvolver novos padrões e definir termos técnicos. Para produzir e introduzir um têxtil inteligente no mercado que enfatize os aspectos de funcionalidade mais do que os de estética, será preciso saber que padrões determinam o seu desempenho, que normas o regulamentam, e que pré-requisitos o produto deve atender. Há normas para têxteis e há normas para eletrônicos, mas não há ainda normas para os produtos híbridos e é preciso desenvolvê-las.

Com respeito à crise internacional e sua influência na disponibilidade orçamentária de apoio à pesquisa e à inovação nos programas da Comunidade Européia, os impactos podem ser positivos. O setor público demonstra interesse em apoiar o setor privado em suas dificuldades econômicas, mas não pretende subsidiar as empresas para que continuem a fazer o que sempre fizeram. Tais subsídios serão cada vez mais destinados a empresas que desenvolvam produtos do futuro. Por exemplo, há grande resistência em subsidiar as dificuldades de sobrevivência da indústria automobilística, mas há forte predisposição em apoiar o desenvolvimento de carros verdes. Este tipo de posicionamento poderá também afetar a indústria T\&C europeia. Tal comportamento poderá beneficiar ainda mais os setores e segmentos, e mais especificamente, as empresas que estejam investindo no desenvolvimento de produtos do futuro. Sob este ponto de vista, a crise enfatizará ainda mais as oportunidades em setores que intensifiquem a geração de inovações tecnológicas como estratégia competitiva.

Quanto à geração de empregos, a União Europeia preocupa-se com os impactos sociais que o desaparecimento de empregos no setor T\&C possa provocar em países em que o percentual de trabalhadores neste setor é muito elevado, como é o caso na Lituânia, por exemplo. Quanto aos países desenvolvidos da União, a relevância da ocupação no setor muda. Analisando o caso da Alemanha, por 
exemplo, o setor ainda emprega cerca de 100 mil pessoas, mas poucos são os que trabalham na manufatura tradicional, estando a maior concentração em trabalhadores da economia do conhecimento, como também é o caso nos países nórdicos, devido ao elevado grau de formação de sua sociedade. Nesta nova ordem em que a T\&C seria impulsionada pela economia do conhecimento, quando uma empresa fecha as portas, seus empregados são rapidamente absorvidos pela empresa vizinha, pela carência de talentos disponíveis. Uma nova restrição surge quando se percebe que poucos jovens talentosos buscam o setor, um fenômeno mundial que não se restringe unicamente ao setor têxtil, pois decorre da redução de procura por áreas de engenharia de uma maneira geral. Por outro lado, na Europa o número de fashion designers formados ultrapassa o que a indústria pode empregar. Tal alteração no comportamento social tem provocado a visita a escolas superiores de moda para alterar as grades curriculares introduzindo conhecimentos sobre materiais e processos têxteis básicos para suprir um pouco a deficiência atualmente encontrada. De maneira geral, entretanto, cada vez mais empresas do setor percebem a inovação como um empreendimento estratégico essencial para a sobrevivência dos negócios.

\subsection{Visita ao Belgian Textile Research Centre (CENTEXBEL)}

Situado no Technologiepark, em Zwijnaarde, a poucos quilômetros de Bruxelas, CENTEXBEL foi criado em 1950 pela Federação das Indústrias Têxteis Belgas (FEDUSTRIA) para ser o centro científico e tecnológico da indústria têxtil belga, tendo por finalidade garantir e reforçar a competitividade dessa indústria. $O$ Centro assume sua missão promovendo projetos de pesquisa sobre algumas das mais recentes evoluções tecnológicas e de suas aplicações na área industrial. Atende, sobretudo, a pequenas e médias empresas oferecendo soluções para problemas por elas aportados e acompanhando a introdução de inovações no ambiente industrial (CENTEXBEL, 2009).

Os entrevistados consideram que a capacidade inovativa de um setor resulta de duas condições: a demanda da indústria para descobrir soluções tecnológicas para seus problemas e uma estrutura legal e normativa pública e privada exigente. Tanto uma como outra impulsionam o CENTEXBEL. O Centro não só oferece 
serviços de certificação como desenvolve ensaios e testes. $O$ interesse crescente pela descoberta de novos materiais e processos têxteis tem sido enfatizado pela conscientização das externalidades indesejáveis de consumo e produção. Neste cenário, existe a necessidade contínua de criação de novos métodos, processos e equipamentos para a realização de ensaios que se adequem às novas normas e regulamentações de uso e de produção. Um ambiente desafiador é a base para o desenvolvimento das instituições de pesquisa e desenvolvimento. Tal ambiente, entretanto, segundo os entrevistados, não pode depender apenas da conscientização espontânea dos consumidores. Na verdade, são as comissões de normalização europeias que investigam os novos produtos e processos, impondo restrições à sua fabricação irresponsável. Segundo o relatório de 2007 (CENTEXBEL, 2007), uma pesquisa realizada pela EURATEX demonstrou que, ao contrário do que supõe o senso comum do empresariado, as normas não são obstáculos à inovação. Ao contrário. Atender às exigências feitas por uma norma contribui para a credibilidade e mais fácil aceitação de um novo produto pelo mercado. São realizadas pesquisas pré-normativas durante as quais desenvolvem métodos de ensaios para inovações, além de oferecer assistência durante o desenvolvimento de novos produtos. De acordo com o último relatório anual, uma das maneiras de vitalizar o potencial inovativo das empresas é por intermédio da promoção da colaboração transetorial. Com este fim, estabelecem redes com diversos atores importantes de outros setores industriais.

Quanto ao desempenho do setor T\&C belga, acreditam que o sucesso do segmento do vestuário seja efêmero, devendo-se, em grande parte, ao aproveitamento de nichos: são os tecidos técnicos e os têxteis para o lar que deverão sustentar e representar o setor T\&C belga no futuro.

\subsection{Visita ao Flanders District of Creativity (FLANDERS DC)}

Flanders DC fica localizada na Vlamingenstraat, na cidade de Leuven (Louvain em Francês). Trata-se de uma organização sem fins lucrativos fundada em 2004 pelo governo flamengo voltada para a promoção da criatividade empreendedora na região de Flanders. Com orçamento garantido em sua maior parte pelo governo de Flandres - 2,3 milhões de euros por ano -, a organização permanece independente sendo inspecionada pelo Ministério de Economia, Ciência Revista Produção Online. Florianópolis, SC, v.11, n. 4, p. 1028-1058, out./dez. 2011. 
e Inovação da Comunidade Flamenga. Possui um corpo gestor que auxilia na elaboração de sua estratégia e que ratifica decisões tomadas pelo seu principal gestor, Pascal Cools. Flanders DC promove a integração de uma rede internacional de parceiros que possam trocar experiências sobre suas melhores experiências. Os membros devem ser regiões criativas denominadas Distritos de Criatividade. A América do Sul não possuía qualquer membro na ocasião da visita. Recentemente, entretanto, em novembro de 2010, a prefeitura da cidade do Rio de Janeiro motivada pelos resultados iniciais da missão - apresentou sua candidatura e foi aprovada como novo Distrito de Criatividade da rede. Um DC deve estar restrito a uma cidade ou localidade - não podendo ser um país, por exemplo - cuja economia seja substancialmente ancorada em IC. A rede de DC realiza anualmente o Fórum Mundial de Criatividade em que líderes governamentais, empreendedores e instituições de conhecimento reúnem-se para a troca de idéias e inspirações. Os DCs também participam de programas europeus para impulsionar a inovação, o empreendedorismo criativo e a internacionalização, e promovem programas de intercâmbio de inovação e criatividade, com visitas a instituições e centros de inovação. De maneira geral, Flanders DC gera, sistematicamente, oportunidades de formação e de estímulo à criatividade empreendedora, a partir da troca de experiências e de visões de mundo diversas. Uma noção mais precisa do papel desempenhado pela organização flamenga pode ser obtida a partir da descrição dos projetos atualmente em curso, listados em seu sítio na Internet.

O termo criatividade empreendedora foi cunhado pelo instituto para substituir a palavra inovação no meio empresarial, pois acreditam que muitos empresários de pequenas e médias empresas associam o conceito de inovação a riscos que não podem assumir. Para Cools, o que se impõe para o futuro é a Gestão da Inovação, em substituição aos investimentos em Gestão da Qualidade. Inovação para Flanders DC é um processo que ultrapassa o enfoque de desenvolver novos produtos. Sob esse aspecto, a criatividade empreendedora é um processo gerador de inovações em múltiplas dimensões: estratégia, organização, processos fabris, marketing, produtos, serviços, mercados, modelos de negócio e gestão. Uma busca contínua que enfoca toda a cadeia de valor.

Segundo o entrevistado, em países como China e Índia, predomina a economia orientada pelos fatores, sob a égide dos custos baixos. No modelo 
predominante na região de Flandres, a economia ainda é orientada pela produtividade, cuja maior força está na eficiência. Em países como a Finlândia, o modelo econômico é orientado pela inovação. A alavanca impulsionadora é a criatividade. Flandres deve migrar para o modelo finlandês se quiser manter-se competitiva na Europa.

A importância da inovação como vetor de desenvolvimento deve-se, entre outros aspectos, às profundas mudanças na composição étnica da sociedade de consumo mundial deflagradas recentemente, pela entrada no sistema de vida ocidental de povos asiáticos e do leste europeu. Além disso, observa-se a contínua e compulsiva redução dos ciclos de vida dos produtos e das próprias tecnologias de base. A criatividade empreendedora é o processo pelo qual uma empresa enfatiza sua melhor competência em uma rede de valor, procurando diferenciar-se de seus competidores por meio da inovação. Wal-Mart mantém cerca de 50 pessoas trabalhando na gestão de suprimentos e inovando sempre. De $75 \%$ a $85 \%$ do PIB da Bélgica são gerados por serviços. No entanto, dos gastos governamentais com P\&D, apenas de $10 \%$ a $15 \%$ são destinados a novos serviços. Por outro lado, a combinação de tecnologias gera muito mais riqueza do que cada tecnologia individualmente.

De acordo com o entrevistado na visita, os próprios institutos de pesquisa, como o CENTEXBEL, algumas vezes apresentam um comportamento rotineiro de pesquisa e desenvolvimento. É a inovação vista puramente como um processo técnico. Talvez por este motivo, quando questionados sobre o futuro das roupas inteligentes, os entrevistados no centro de P\&D tenham se mostrado céticos quanto à disseminação do uso dessas roupas, baseados em uma visão conservadora do comportamento de consumo da sociedade, alheios à capacidade de novos empresários encontrarem soluções comerciais para a disseminação de artigos predominantemente funcionais. Para Pascal Cools, diretor do Flanders DC, o empresário flamengo é orientado pela produtividade e pela eficiência, atribuindo pouco valor à criatividade como fator de competitividade. Por outro lado, profissionais de setores criativos são resistentes quanto a adotar uma abordagem mais eficiente, condicionada por resultados práticos e economicamente sustentáveis. Sendo assim, as atividades de Flanders DC têm por objetivo tornar os empreendedores mais criativos e tornar os criadores mais empreendedores. 
A indústria do vestuário de Flandres tem à sua disposição uma rede institucional de grande capacidade técnica e científica. Além do CENTEXBEL, o Interuniversity Microelectronic Center (IMEC), que realiza P\&D em nanoeletrônicos aplicados aos têxteis, e o Interuniversity Institute for Biotechnology (VIB) poderão apoiar e fomentar a criatividade empreendedora da indústria da moda belga. Esses centros devem, no entanto, estar atentos às oportunidades criadas pelos profissionais de moda da região, não se restringindo apenas à grande indústria de têxteis técnicos.

\subsection{Visita ao Flanders Fashion Institute (FFI)}

Estabelecido em 1998 para apoiar a geração de empregos na indústria da moda e promover designers local e globalmente, o FFI é suportado financeiramente pelo governo de Flandres. O FFI faz parte de um complexo de moda, criado em 2003, a ModeNatie, compartilhando o mesmo prédio o MoMu (museu de moda), o Departamento de Moda da Real Academia de Belas Artes, o corpo editorial da revista A Magazine e uma biblioteca de moda, além do próprio FFI ( 2009). Localizado na Nationalestraat, na cidade de Antuérpia, o FFI administra uma rede de talentos formada por designers de moda graduados, novos talentos e de renomados profissionais em atividade na Bélgica. Atua também como base para redes de profissionais criativos, como fotógrafos, designers gráficos e maquiadores. O FFI procura identificar as necessidades desses profissionais e oferecer soluções apropriadas. A partir de estreita colaboração de consultores de negócios de moda, o instituto acompanha as carreira dos recém formados até que se tornem empreendedores independentes. O FFI também ajuda os designers a estabelecer, expandir e reestruturar seus negócios existentes. De maneira geral, o FFI atua como intermediário entre a indústria e os designers, facilitando a realização de projetos criativos e inovadores. Assim como o Flanders DC, seu corpo de diretores é composto de profissionais da alta administração de diversas instituições públicas e privadas.

O departamento de moda da Real Academia de Belas Artes possui um programa integrado de quatro anos de bacharelado e mestrado. Atualmente, contam com 163 alunos, 90\% dos quais estrangeiros, de 33 nacionalidades. A conjunção de jovens artistas de diversas nacionalidades é encarada como uma das alavancas Revista Produção Online. Florianópolis, SC, v.11, n. 4, p. 1028-1058, out./dez. 2011. 
para a formação de talentos de moda belgas. Este aspecto se coaduna com a opinião do entrevistado na EURATEX, de que a sociedade belga é especialmente talhada para a internacionalização, principalmente devido à formação em quatro línguas.

Um dos entraves à penetração de designers de moda no ambiente industrial são as lacunas entre a linguagem de moda e a linguagem técnica. Em geral, profissionais criativos de moda desconhecem conceitos e termos técnicos empregados na indústria têxtil, o que resulta em dificuldades de comunicação entre os projetistas e os produtores. A formação de designers deve considerar a introdução dos alunos em termos, princípios, conceitos, técnicas e métodos básicos empregados no meio produtivo. Noções básicas sobre administração financeira de negócios também deve ser considerada para a formação empreendedora de profissionais criativos. Os profissionais do futuro deverão ter seu foco em prototipagem.

A indústria europeia, e mais especificamente a indústria de vestuário belga, deverá se dividir entre as duas extremidades da cadeia de valor: criação e controle da comercialização. Ou seja, a produção de roupas de massa deverá migrar definitivamente para os países com políticas de desenvolvimento fortemente ancoradas no setor T\&C, como os países asiáticos, africanos e da América Central e Caribe. As atividades intensivas em tecnologia e conhecimento, entretanto, deverão se desenvolver, assim como o controle da distribuição e comercialização de produtos. Artigos de luxo ou de alta diferenciação poderão ser produzidos por empresas da UE, devido ao elevado nível de integração necessária entre projeto, desenvolvimento e produção, e a consequente proximidade geográfica requerida entre essas atividades.

\subsection{Visita ao Comité Internationale de la Rayonne et des Fibres Synthétiques (CIRFS)}

CIRFS é o órgão representativo da indústria de fibras manufaturadas europeia. Baseado na Avenue E. Van Nieuwenhuyse, 6, em Bruxelas, o CIRFS atua em todas as áreas de interesse comum de seus membros. A instituição produz análises de comércio exterior sobre seus países membros e clientes assim como 
sobre países competidores, cobrindo um total de 45 países (CIRFS, 2009). Um estudo anual é realizado sobre o uso e a composição de fibras de todos os produtos consumidos na União Europeia, sendo que o CIRFS publica, também com periodicidade anual, um relatório estatístico.

Segundo estudos de mercado mencionados na entrevista, os consumidores declararam estar cada vez mais preocupados com as condições em que a produção ocorre, no que diz respeito aos danos ao meio ambiente e à exploração do trabalho. Mas, na hora de comprar, escolhem pelo preço mais baixo. As melhores pesquisas são realizadas pelos grandes varejistas para dar suporte à forte competição que têm entre si. Os grandes varejistas financiam estudos científicos consistentes para não serem atingidos por pesquisas que os acusem de irresponsabilidade socioambiental. Quanto às novas aplicações e desenvolvimentos tecnológicos no vestuário, avaliam que um cliente não comprará uma roupa mais barata se ela não atender os requisitos básicos de desempenho; já no segmento de roupas profissionais, elas assumem importância cada vez maior na imagem de uma empresa. Seria importante reunir os designers de moda aos desenvolvedores de novas aplicações. Por outro lado, os estilos de vida modernos aproximam as aplicações: roupas para jogging e roupas para ir a uma discoteca podem ter requisitos muito similares. Avalia que os novos desenvolvimentos deverão afetar os produtores de máquinas. Atualmente, o modelo baseia-se em produtividade e eficiência. Em futuro próximo, na Europa, as máquinas têxteis deverão estar focadas em qualidade e na capacidade de efetuar trocas rápidas de cores, fios e tecidos, rodando em pequenas metragens.

\subsection{Visita à PICANOL}

A fábrica está situada na cidade de leper, na rua Ter Waarde, 50, mas obras estavam em curso para mudança de endereço, na mesma cidade. Picanol pertence ao Picanol Group (PICANOL, 2009). O grupo evoluiu recentemente de um fabricante de máquinas de tecer tradicional para se tornar um fornecedor mundial de soluções completas para a indústria têxtil e para outras indústrias. Possui uma política ativa de inovação e tem por objetivo investir, anualmente, $5 \%$ de sua receita em pesquisa e desenvolvimento. O Grupo Picanol possui instalações na Ásia, Europa e Estados Unidos, e emprega 2.200 pessoas em todo o mundo. As ações da empresa estão no 
mercado, mas o controle familiar é de $59 \%$ do total. A vantagem de ter um decisor predominante consiste em permitir uma visão de futuro de longo prazo, ou seja, a visão é menos volátil do que se a empresa fosse controlada pelo humor de acionistas pulverizados pelo mercado. Há investimentos previstos da ordem de 16 milhões de euros. A empresa fabrica seus próprios circuitos porque precisa de poucas unidades para atender suas máquinas, escala insuficiente para poder trabalhar com grandes fabricantes. Outro fator de verticalização refere-se à necessidade de incorporar pequenos fornecedores de dispositivos que precisam acompanhar tecnologicamente o nível de suas máquinas em requisitos como resistências a tensões diversas e atrito, leveza e durabilidade.

O futuro dos fabricantes de máquinas de tecer estará condicionado pelo aumento da versatilidade e da flexibilidade dos sistemas de produção. Fatores de desempenho como qualidade e produtividade passam a ser default entre competidores. Até mesmo os fabricantes de jeans estão migrando para os teares de pinças, em parte devido ao uso crescente de trama elástica. Isto significa que estão priorizando a rapidez da troca de artigos e a maior diversidade de tramas (títulos e cores) que o sistema de pinça possui quando comparado aos sistemas jato de ar e projétil, cujo principal atributo é a alta velocidade de inserção. Deve-se observar, entretanto, que a velocidade de inserção das máquinas com pinças aumentou muito nos últimos anos, aproximando-se dos níveis apresentados pelos outros sistemas. Consideram que os fabricantes de tecidos brasileiros deveriam seguir os modelos das empresas Cataguases e Renaux, substituindo suas máquinas por modelos com pinças. Duas grandes empresas fabricantes de jeans do Brasil pediram que avaliassem as vantagens e inconvenientes do sistema para seus modelos de produção. Foi citado o caso da Fábrica da Pedra, em Sergipe. Originalmente pertencente a Delmiro Gouveia, passou por reestruturação e seus tecidos suprem fabricantes de artigos para o lar de qualidade e artigos vendidos em grandes varejistas de massa. A tecelagem possui teares Sulzer, Tsudakoma e teares de pinça Picanol. 


\section{INSPIRAÇÕES PARA IMPULSIONAR A CRIATIVIDADE EMPREENDEDORA}

A atuação em nichos é, sem dúvida, a principal estratégia a ser seguida por um país que não queira competir com asiáticos e latinos que tenham nas exportações têxteis sua principal fonte de desenvolvimento socioeconômico. Instituições de P\&D com alta capacidade de desenvolvimento de produtos e tecnologias de última geração, como é o caso das instituições europeias citadas neste trabalho, são importantes para uma economia criativa, mas não são facilmente criadas. O que não quer dizer que iniciativas como as que foram adotadas pela Coreia do Sul para desenvolver em uma década suas instituições de P\&D devam ser descartadas. O Brasil possui as bases para o desenvolvimento de projetos dedicados aos problemas têxteis em instituições de ciência, tecnologia e inovação que devem ser aproveitadas como diferencial comparativo. Mas há outras iniciativas que poderão ser empreendidas em curto prazo que terão reflexos quase imediatos na impulsão a ser dada ao setor. Trata-se de medidas de multiplicação de ações de amparo e estímulo à criatividade empreendedora de pequenas e médias empresas do setor. A ser mais bem entendido por órgãos como o SEBRAE, o modelo de gestão do Flanders DC poderá vir a facilitar a rápida disseminação de conceitos de inovação em toda a cadeia de valor. A participação de cidades brasileiras que têm na indústria da moda um de seus pilares de desenvolvimento econômico na rede de Distritos de Criatividade pode ser uma medida de cunho político a ser considerada. A interação entre designers de moda e ambiente produtivo, sinalizada tanto pelo diretor do Flanders DC quanto pela diretora do Flanders Fashion Institute, é medida a ser deflagrada de forma sistêmica em projetos que congreguem as organizações de formação e o meio empresarial.

Quanto ao ambiente produtivo, a visita ratificou a noção estabelecida em estudos mais recentes empreendidos pelo IPTM. Tais estudos sugeriram a necessidade de reforma estrutural do sistema produtivo brasileiro. Grandes empresas de produção em massa deverão dar lugar a empresas mais versáteis e flexíveis, de maneira a suprir necessidades de pequenos empreendedores criativos, no que diz respeito à oferta de novos insumos, de grande diversidade e em pequenas séries. 
A abordagem dos desafios do setor a partir da indústria da moda oferece um outro olhar sobre as questões de futuro que precisam ser equacionadas. Assim como é sugerido por uma leitura transversal das entrevistas, a capacidade de inovar da rede de valor pode ser alcançada por intermédio da ativação de diferentes competências. O enfoque de instituições de P\&D é naturalmente intensivo em tecnologia; instituições de apoio à criatividade empreendedora, por outro lado, estão mais preocupadas com a dinâmica socioeconômica que envolve os indivíduos criativos. Essas duas maneiras de encarar o mesmo problema não são incompatíveis entre si, ao contrário, são complementares; mas muitas vezes o diálogo entre atores representativos de cada grupo não é estabelecido como deveria.

O desenvolvimento de regiões criativas depende de muitos elementos e de múltiplas interações. Diferenças regionais em termos de localização geográfica, estrutura industrial, capital social, capital humano, capital cultural e capital institucional (UNCTAD, 2010), impedem a formulação de um método universal de desenvolvimento. Os pré-requisitos da economia criativa estão emergindo a partir dos processos de trocas e de benchmarking dos diferentes estágios de desenvolvimento de cada região que ocorrem na rede mundial de Distritos de Criatividade. O conhecimento dessas experiências pode levar outras regiões a identificar suas forças e fraquezas e elaborar suas próprias estratégias, a partir dos parâmetros e das condições econômicas e sociais locais. Políticas públicas, particularmente, aquelas relacionadas à ciência e tecnologia, aos setores industriais, à educação e às artes, necessitam de nova ênfase na economia criativa.

A OECD (1996, p.19) distingue três prioridades para as regiões que desejam se mover na direção da economia criativa: (a) ampliação da difusão do conhecimento; (b) valorização do capital humano; (c) promoção de mudança organizacional. O papel central das políticas públicas na economia criativa é estabelecer as condições adequadas e os incentivos que facilitem e promovam o aprendizado de indivíduos e organizações, estimulando a aprendizagem em rede, intra e inter-regionalmente. As experiências dos Distritos de Criatividade, assim como de outras iniciativas de economia criativa (cf. UNCTAD, 2010, p. 253-254; cf. também LONDON... 2005; 2006) mostram que se trata de processos complexos que requerem a interação e a colaboração de diferentes atores e o projeto de instituições de suporte realmente 
efetivas. Estas experiências representam claras oportunidades e são fontes de inspiração, mas, também, revelam fraquezas e barreiras que precisam ser removidas.

Suzigan et alii (2007) sugerem princípios para a formulação de políticas que podem ser aplicáveis neste estudo. Ressaltam a importância de considerarem-se princípios de mercado e decisões privadas, evitando assumir como objetivo a simples criação de arranjos ou sistemas. Além disso, observam que políticas devem (op. cit., p.180):

i. Oferecer condições para os atores locais empregarem suas capacidades de mobilização do sistema em favor do desenvolvimento, o que significa que tais atores não podem ser substituídos por políticas, devendo-se evitar medidas que inibam o desenvolvimento autônomo do sistema e de suas forças sociais.

ii. Requerer o comprometimento dos atores locais, seja através de contribuições seja pela assunção de atividades coletivas complementares.

iii. Adequar-se aos diferentes tipos de arranjos ou sistemas assim como aos seus estágios de desenvolvimento.

Além disso, os autores enfatizam medidas que devem ser consideradas para enfrentar problemas comumente encontrados em infraestrutura, instituições locais, organização para ações estratégicas, governança e poluição.

Em termos objetivos, cada uma das dezesseis dimensões estruturadas pela Arthur D. Little (op. cit.) poderá ser alvo de levantamentos de capacidades institucionais, de políticas preexistentes e de ações que vêm sendo planejadas isoladamente para impulsionar a criatividade dos negócios em regiões selecionadas. Apoiados em uma coordenação geral ágil e efetivamente representativa dos genius loci, projetos poderão ser desenvolvidos a partir da estruturação inicial da rede institucional e do arcabouço de políticas e de ações, priorizando-se atividades produtivas e setores econômicos que demonstrem o dinamismo e a capacidade de multiplicação adequados ao ritmo de desenvolvimento de um DC.

Ao imprimir a característica de indústria criativa ao setor T\&C brasileiro como um todo, impõe-se um maior distanciamento da visão excessivamente tecnológica da inovação, fazendo emergir a importância dos ativos intangíveis e das abordagens com maior carga de incertezas, típicas das indústrias criativas. Este distanciamento favorece a busca de métodos de apoio à criatividade empreendedora como forma de capacitação do setor e de mudança de seu perfil. Ao mesmo tempo, a necessidade Revista Produção Online. Florianópolis, SC, v.11, n. 4, p. 1028-1058, out./dez. 2011. 
de aproximação dos discursos dos segmentos produtivos e dos empreendedores de moda é enfatizada.

\section{CONSIDERAÇÕES FINAIS}

Levantamentos de dados de comércio internacional de T\&C, posteriores à missão, mostram que as discrepâncias nos dados de comércio exterior da indústria T\&C belga em sua comparação com gigantes globais apresentam grandes variações de ano para ano. Produtos de vestuário não seguem um padrão de agregação de valor constante, ou pelo menos estável, como se supunha. Há grande variação anual nos dados da UNCTAD no que diz respeito aos valores obtidos assim como aos volumes exportados nos diferentes capítulos do sistema harmonizado. É fato, entretanto, que a posição belga melhorou ainda mais nos últimos anos.

As entrevistas não apresentaram indícios de que um sistema organizado está sendo posto em prática e muito menos que o desempenho belga possa ser atribuído a uma ação coordenada de inovação para o setor com este propósito. Os entrevistados em sua maioria consideraram que o país continua a dever sua representatividade no mercado internacional aos têxteis para o lar, sobretudo carpetes e têxteis técnicos. No vestuário, os entrevistados estimam que os resultados obtidos sejam fruto do aproveitamento de nichos de mercado, para o que corroboram as variações do valor em dólar por quilograma, observadas anualmente em diversos artigos belgas. Entretanto, a falta de evidências de que um sistema coordenado de inovação estaria sendo propositalmente posto em marcha para alavancar a indústria T\&C belga não invalida os objetivos da visita. Na verdade, individualmente, cada um dos atores demonstrou a competência institucional que está disponível para sua indústria. Além de apresentarem sistemas de gestão muito racionais, seus modelos administrativos concentram talentos em áreas-chave, procurando sempre fazer valer a capacidade sinérgica de suas redes para suplementar as necessidades de trabalho envolvidas, mesmo quando há claras demonstrações de antagonismos. A União Europeia amplifica ainda mais as capacidades institucionais nacionais, e a rede de pesquisadores, consultores e empresários, sempre inicialmente ativada com enfoque local, não se furta em ampliar seus elos para toda a região quando necessário para a resolução de um 
problema. A ação da Comunidade Europeia e da EURATEX oferecendo financiamentos com regras claras que estimulam a atuação em rede entre atores empresariais e acadêmicos, entretanto, é uma ação coordenada de estímulo à inovação, no sentido amplo.

A formulação de políticas de desenvolvimento regional que adotem princípios das economias criativas pode ser uma alternativa aos modelos excessivamente pragmáticos de desenvolvimento regional, nos quais a coordenação das competências de uma região está centrada na racionalização econômica e teleológica das atividades produtivas. Estudos podem ser realizados em arranjos produtivos de confecção justamente para confrontar características das diferentes abordagens.

\section{REFERÊNCIAS}

AGÊNCIA BRASILEIRA DE DESENVOLVIMENTO INDUSTRIAL (ABDI). Estudo prospectivo setorial têxtil e confecção. Brasília: ABDI, 2009a.

AGÊNCIA BRASILEIRA DE DESENVOLVIMENTO INDUSTRIAL (ABDI). Estudos setoriais de inovação: indústria têxtil e de vestuário. Brasília: $A B D I, 2009 b$.

AGÊNCIA BRASILEIRA DE DESENVOLVIMENTO INDUSTRIAL (ABDI). Boletins de acompanhamento setorial. Têxtil e confecção. Brasília: ABDI, mar. 2009c.

ARTHUR D. LITLLE, Inc. Clever practices to boost the creative and innovative potencial of regions: inspiration for the districts of creativity. Creativity world forum. Gent, nov, 2006.

BENKO, Georges. La science régionale. Paris: PUF. 1998.

BNDES. critérios para a atuação do bndes em arranjos produtivos locais. BNDES, Brasília, 2004a.

BNDES. Arranjos produtivos locais e desenvolvimento. Versão preliminar. BNDES: Brasília, 2004b.

BRAUN, Erik; LAVANGA, Mariangela. An international comparative quick scan of national policies for creative indutries. European Institute for Comparative Urban Research (EURICUR). Erasmus University Rotterdam. 2007.

BRUNO, Flavio da Silveira. Do mercado interno à globalização: governo, instituições e empresários planejando o futuro do setor. In Globalização da economia têxtil e de confecção brasileira: empresários, governo e academia unidos pelo futuro do setor. Rio de Janeiro: Editora SENAI. 2007. Capítulo 6, p. 314-315. 
BRUNO, Flavio da Silveira ; FILIPECKI, Ana Tereza Pinto ; MIRANDA, José Maria Simas de ; ABRANCHES, Gerson Pereira ; LÚCIDO, Gil L. A. ; SOARES JR, Enio . Panorama Setorial. Relatório técnico. Centro de Gestão e Estudos Estratégicos. 2007.

BRUNO, Flavio da Silveira; BRUNO, Ana Cristina Martins. O papel do setor têxtil e de confecção brasileiro na liderança de um modelo sustentável de desenvolvimento. Revista Produção Online, v.9, n.3, p. 551-571, set. 2009. Disponível em: <http://www.producaoonline.org.br/index.php/rpo/article/view/319/496>.

BRUNO, Flavio da Silveira; BRUNO, Ana Cristina Martins; CAMARGO, Paula de Oliveira; BECKER, Cristina Bokel. Rio de Janeiro, Distrito de Criatividade: ações para o desenvolvimento de economias de aglomeração de criatividade na cidade. REDIGE, v.2, n.1, p. 120-131, mar. 2011. Disponível em:

<http://www.cetiqt.senai.br/ead/redige/index.php/redige/article/download/87/143>.

CENTEXBEL. Rapport annuel 2007. Disponível em

$<$ http://www.evonet.be/ centex02/bigimages_2008/jaarverslag_rapportannuel_2007.PDF>. Acesso em 13 jan. 2009.

CENTEXBEL. La recherche textile. Disponível em:

<http://www.centexbel.be/Fr/product_research.htm>. Acesso em: 13 jan. 2009.

CIRFS. Home page. Disponível em: < http://www.cirfs.org/>. Acesso em: 28 fev. 2009.

DE VOLDERE, Isabelle; JANSSENS, Eva; ONKELINX, Jonas; SLEUWAEGEN, Leo. The creative economy: challenges and opportunities for the DC regions. Research report. Vlerick Leuven Gent Management School, April, 2006.

EUROPEAN APPAREL AND TEXTILES ORGANISATION (EURATEX). Mission. Disponível em: <http://www.euratex.org/content/mission.html>. Acesso em: 13 jan. 2009.

EUROPEAN COMISSION. The economy of culture in Europe. Directorate-General for Education and Culture. October, 2006.

FFI. Home page. Disponível em: < http://www.ffi.be/index.asp>. Acesso em: 28 fev 2009.

FLANDERS DC. Projetos. Disponível em: <http://www.flandersdc.be/view/nl/ 2260332-All+projects.html>. Acesso em: 28 fev. 2009.

FLORIDA, Richard. Toward the learning region. Futures, v.27, n.5, p. 527-536, 1995.

FLORIDA, Richard. The rise of the creative class. New York: Basic Books. 2002. GARCIA, Renato; MOTTA, Flavia; SCUR, Gabriela; LUPATINI Márcio; CRUZMOREIRA, Juan Ricardo.. Esforços inovativos de empresas no Brasil: uma análise 
das indústrias têxtil-vestuário, calçados, móveis e cerâmica. São Paulo em Perspectiva, v. 19, n. 2, p. 60-70, abr./jun. 2005.

INSTITUTO BRASILEIRO DE GEOGRAFIA E ESTATÍSTICA (IBGE). Pesquisa de inovação tecnológica 2005. Rio de Janeiro: IBGE, 2005.

INSTITUTO DE PROSPECÇÃO TECNOLÓGICA E MERCADOLÓGICA (IPTM). Mercado belga: C\&T e inovação. Relatório. IPTM/SENAI/CETIQT. 2008.

JONES, E.; STANTON, N. A.; HARRISON, D. Applying structured methods to ecoinnovation: an evaluation of the Product Ideas Tree diagram. Design Studies, v.22, n.6, p.519-542, nov. 2001.

KAPLINSKY, Raphael. Sustaining income growth in a globalising world: the search for the Nth rent. Mimeo, Institute of Development Studies, University of Sussex., jan. 2004.

LESLIE, Deborah. Creative cities. Editorial. Geoforum, n.36, p.403-405, 2005. LONDON DEVELOPMENT AGENCY. Strategies for creative spaces: phase 1 report. Sept. 2005. Disponível em: http://www.creativelondon.org.uk. Acesso em: 20 março 2011.

LONDON DEVELOPMENT AGENCY. Strategies for creative spaces: lessons learned. Nov. 2006. Disponível em: <http://www.creativelondon.org.uk>. Acesso em: 20 março 2011.

LONG, Joshua. Sustain creativity in the creative archetype: the case of Austin, Texas. Cities, n.26, p. 210-219, 2009.

LUNDVALL, Bengt-Aake. National systems of innovation: towards a theory of innovation and interactive learning. London: Pinter Publishers, 1992.

LUNDVALL, Bengt Aake. National systems of innovation: analytical concept and development tool. Paper presented at DRUID $10^{\text {th }}$ anniversary summer conference. Copenhagen, 27-29 jun. 2005.

LUPATINI, M. Relatório setorial preliminar: têxtil e vestuário. Rio de Janeiro: FINEP, 2004.

MANZINI, Ezio; VEZZOLI, Carlo. Product-service systems and sustainability: opportunities for sustainable solutions. Paris: United Nations Environment Programme. 2002a.

MANZINI, Ezio; VEZZOLI, Carlo. O desenvolvimento de produtos sustentáveis: os requisites ambientais dos produtos industriais. São Paulo: EDUSP. 2002b.

MANZINI, Ezio; VEZZOLI, Carlo. Design para a inovação social e sustentabilidade: comunidades criativas, organizações colaborativas e novas redes 
projetuais. Coordenação de tradução Carla Cippola. Rio de Janeiro: E-papers. 2008. (Cadernos do Grupo Altos Estudos; v.1).

MINISTERIAL CREATIVE INDUSTRIES STRATEGY GROUP. Creative industries mapping document. 2001. Disponível em:

<http://www.culture.gov.uk/reference_library/publications/4632.aspx>. Acesso em: 27 fev. 2009.

ORGANSATION for ECONOMIC CO-OPERATION and DEVELOPMENT (OECD). The knowledge-based economy. Report. OCDE/GD(96)102. Paris, 1996.

ORGANSATION for ECONOMIC CO-OPERATION and DEVELOPMENT (OECD). Science, technology and industry scoreboard 2005. Anexe A. Paris, 2005.

PICANOL. The Picanol Group. Disponível em:

<http://www.picanolgroup.com/picgroupsite/EN>. Acesso em: 28 fev. 2009.

SCHUMPETER, Joseph. The theory of economic development: an inquiry into profits, capital, creit, interests, and the business cycle. Translated from the German by Redvers Opie. 10 ed. Transaction Publishers. New Brunswick. 2004.

SCHUMPETER, Joseph. Capitalism, socialism and democracy. 2 ed. Martino Fine Books. Connecticut. 2011.

SEBRAE. Arranjos produtivos locais: perfil das concentrações de atividades econômicas no Estado do Rio de Janeiro. Rio de Janeiro: SEBRAE, 2004.

SILVA, João Luiz de Figueiredo. Indústria da moda de luxo: economia criativa e cidade. Revista da ESPM, set./out. 2008.

SUZIGAN, Wilson; FURTADO, João; GARCIA, Renato; Sampaio, Sérgio. Local production and innovation systems in the state of São Paulo, Brazil. The 43 European Congress of the Regional Science Association (ERSA 2003), University of Jyvaskyla, Finland, 2003.

SUZIGAN, Wilson; FURTADO, João; GARCIA, Reanato. Designing policies for local production systems. EconomiA, Brasília (DF), v.8, n.1, p.161-186, Jan./Apr. 2007.

TENDLER, Judith. Transforming local economies: lessons from the northeast Brazilian experience. Prepared under the auspices of the MIT/BN Project (Massachusetts Institute of Technology Department of Urban Studies and Planning/Bank of the Northeast) 4 Aug 2001. Presented at the OECD/State of Ceará State Government Meeting on Foreign Direct Investment, Fortaleza, 12 Dec 2002. 
UNCTAD. Creative Economy Report 2010. United Nations, 2010.

VANOLO, Alberto. The image of the creative city: some reflections on urban branding in Turin. Cities, n.25, p.370-382, 2008.

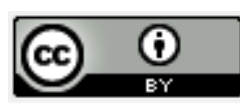

Artigo recebido em 28/06/2010 e aceito para publicação em 18/09/2011. 